Comparison of the responses of peritoneal macrophages from Japanese flounder (Paralichthys olivaceus) against high-virulent and low-virulent strains of

\title{
Edwardsiella tarda
}

Keiko Ishibe ${ }^{\text {a }}$, Kiyoshi Osatomi ${ }^{\text {b }}$, Kenji Hara ${ }^{\text {b }}$, Kinya Kanai ${ }^{\text {c }}$, Kenichi Yamaguchi ${ }^{\text {d, }}$ Tatsuya Oda ${ }^{\mathrm{d}, *}$

a Graduate School of Science and Technology, Nagasaki University, Nagasaki 852-8521, Japan

${ }^{b}$ Department of Marine Biochemistry, Faculty of Fisheries, Nagasaki University, Nagasaki 852-8521, Japan

${ }^{\mathrm{c}}$ Labolatory of Fishpathology, Faculty of Fisheries, Nagasaki University, Nagasaki 852-8521, Japan

${ }^{\mathrm{d}}$ Division of Biochemistry, Faculty of Fisheries, Nagasaki University, Nagasaki 852-8521, Japan

Keywords: Edwardsiella tarda; Bacterial infection; Japanese flounder; Fish peritoneal macrophages; Phagocyte; Oxidative burst; Chemiluminescence

*Corresponding author. Tel.: +81 95819 2831; fax: +81 958192799.

E-mail address: t-oda@nagasaki-u.ac.jp (T. Oda) 


\section{Abstract}

In vivo infection studies in Japanese flounder (Paralichthys olivaceus) demonstrated that the number of viable cells of the virulent strain (NUF251) of Edwardsiella tarda increased gradually in kidney and hepato-pancreas after intraperitoneal injection, but the low virulent strain (NUF194) did not. To gain insight into the virulence factor of $E$. tarda, in vitro responses of Japanese flounder (Paralichthys olivaceus) peritoneal macrophages to these strains were compared in terms of phagocytosis, bactericidal activity, and reactive oxygen species (ROS) generation as measured by chemiluminescence (CL) responses. Microscopic observation revealed that these two strains of E. tarda were phagocytosed by the peritoneal macrophages, and there was no significant difference in the mean numbers of ingested bacteria per macrophage between these strains. A gradual increase in the number of viable cells of the highly virulent strain within macrophages was observed during 9 h post-phagocytosis, whereas no significant replication of the low virulent strain within macrophages was detected. These results suggest that the virulent strain of E. tarda has an ability to survive and replicate within macrophages, while the low virulent strain has no such ability. When the peritoneal macrophages were exposed to the opsonized low virulent E. tarda strain, a rapid increase in CL response was induced. However, the highly virulent strain caused only background level of CL response. By the subsequent stimulation with phorbol myristate acetate, the macrophages exposed to the virulent $E$. tarda strain showed extremely higher CL response than that of the one exposed to the low virulent $E$. tarda strain. These results suggest that the virulent $E$. 
tarda prevents the activation of ROS generation system during the bacterial phagocytosis, and such system is still capable to respond to other stimulation. The virulent strain significantly reduced the CL response induced by xanthine/xanthine oxidase system, while the low virulent strain had almost no effect. Furthermore, the virulent strain showed greater resistibility to $\mathrm{H}_{2} \mathrm{O}_{2}$ than the low virulent strain. Our results suggest that the virulent strain of $E$. tarda is highly resistant to ROS, and such ability might allow the organism to survive and multiply within phagocytes, and may serve to disseminate $E$. tarda throughout the host during in vivo infection.

\section{Introduction}

Edwardsiella tarda, a Gram-negative bacterium, is the etiological agent of several diseases of marine and freshwater fish. Edwardsiellosis caused by this bacterium has been responsible for significant losses in fish culture industry, particularly in Japanese eel (Anguilla japonica), channel catfish (Ictalurus punctatus), and Japanese flounder (Paralichthys olivaceus), and these infectious diseases are often associated with poor water quality and stress [1]. The disease signs may include small cutaneous lesions that can develop into necrotic abscesses, distended abdomen and swollen anus due to the accumulation of ascitic fluid, pigment loss, enlarged kidney, and abscesses on internal organs [1]. In addition to fish, E. tarda has been found to infect other species including amphibians [2], reptiles [3], birds [4], and mammals including humans [5]. In spite of the importance of $E$. tarda as a fish pathogen and the increasing significance of 
the disease, little is known about the pathogenesis of E. tarda infection. Some potential virulence factors of this bacterium have been suggested, namely dermatotoxin [6], hemolysis [7], ability to invade epithelial cells [8], and capability of surviving in phagocytes [9].

Phagocytosis, a fundamental defense mechanism in most animal species including fish, is mediated by phagocytic cells such as neutrophils, monocytes and macrophages. It is well-known that the antibacterial defense mechanism of these cells is mediated by the production of reactive oxygen species (ROS) [10]. Since the production of ROS has been correlated with killing bacteria by phagocytic cells in fish and humans [10], the ability of E. tarda to survive within phagocytic cells and even replication may serve to disseminate the bacteria throughout the host. Previous study demonstrated that a strain of E. tarda which is highly virulent to eel induced no significant level of ROS generation by eel neutrophils as measured by luminol-enhanced chemiluminescence, a technique commonly used to measure ROS generation by phagocytic cells, whereas $E$. coli and V. anguillarum induced potent CL in the same assay system [11]. The underlying mechanism for this is still unclear, but it seems that this finding may be related to the ability of $E$. tarda to survive inside host phagocytic cells as a virulence factor described above. Similar to E. tarda, it has been reported that the ability to survive inside host macrophages is an essential virulence requirement for Salmonella [12], and Salmonella phoP mutants that cannot survive in macrophages are avirulent [13].

To gain further insight into the virulence factor of $E$. tarda, in this study, we 
examined the early responses of Japanese flounder peritoneal macrophages against two strains of E. tarda with different virulence potential. The results indicated that the highly virulence strain has the ability to resist to ROS, and is capable to survive and multiply within macrophages, whereas the low virulent stain has no such abilities.

\section{Materials and methods}

\subsection{Chemicals}

L012, a highly sensitive ROS specific chemiluminescence probe, and superoxide dismutase (Cu, Zn-SOD) (3800 units/mg of protein, from bovine erythrocytes) were purchased from Wako Pure Chemical Industry, Co., Ltd. (Osaka, Japan). Other chemicals were of the highest grade commercially available.

\subsection{Fish}

Uninfected healthy Japanese flounder Paralichthys olivaceus were obtained from local commercial farms (Nagasaki, Japan). The mean body length and weight of the fish were $31 \pm 2 \mathrm{~cm}$ and $319 \pm 40 \mathrm{~g}$, respectively. The fish were kept in a flow-through system (1000 L tank), and were fed flounder pelleted food daily.

\subsection{Bacterial strains}


Two strains of E. tarda (NUF251 and NUF194) isolated from Japanese flounder and eel pond water, respectively were used in this study. Strain NUF251 belonging to serotype A, is known to be highly virulence and pathogenic to Japanese eel and Japanese flounder, whereas strain NUF194 is found to be relatively low virulence [14, 15]. These strains were stored in nutrient medium with $10 \%$ glycerol at $-80^{\circ} \mathrm{C}$, and subcultured on nutrient agar medium at $27^{\circ} \mathrm{C}$ for $24 \mathrm{~h}$ prior to the onset of experiments. The cultured bacterial cells were harvested in Dulbecco's modified phosphate-buffered saline (PBS) and washed twice with PBS by centrifugation $\left(9,000 \mathrm{xg}, 1 \mathrm{~min}\right.$, at $\left.4^{\circ} \mathrm{C}\right)$. The number of colony forming units (CFU) was determined by plating 10 -fold serial dilutions on agar plates, and the bacterial suspension was diluted with PBS to the desired concentration.

\subsection{Opsonization of bacteria}

Equal volume of bacterial cell suspension in PBS and 50\% of freshly prepared normal serum from Japanese flounder in PBS were mixed. After incubation at $25^{\circ} \mathrm{C}$ for $30 \mathrm{~min}$, the bacterial cells were diluted with PBS to appropriate cell density.

\subsection{Preparation of peritoneal macrophages}

The fish were anaesthetized with $0.02 \%$ of 2-phenoxy ethanol, and $5 \mathrm{ml}$ of PBS 
containing $40 \mathrm{unit} / \mathrm{ml}$ of heparin were then injected through the peritoneal wall at the midline using $5 \mathrm{ml}$ syringe attached with a $25 \mathrm{G}$ needle. Using the same syringe system, peritoneal fluid was gently withdrawn from the specimen. This procedure was repeated twice and the harvested cell suspensions were pooled in siliconized centrifuge tubes on ice. The cells were washed with PBS by centrifugation $\left(200 \mathrm{x} \mathrm{g}, 10 \mathrm{~min}\right.$ at $\left.4{ }^{\circ} \mathrm{C}\right)$. The final cell pellet was resuspended in a small amount of PBS, and was layered over $5 \mathrm{ml}$ Percoll in $7 \mathrm{ml}$ polycarbonate centrifuge tube (density: $1.075 \mathrm{~g} / \mathrm{ml}$ ) in which continuous density gradient was preformed by centrifugation $\left(20,000 \mathrm{x} \mathrm{g}, 30 \mathrm{~min}\right.$ at $\left.20^{\circ} \mathrm{C}\right)$, and centrifuged at $490 \mathrm{x}$ g for $60 \mathrm{~min}$ at $20^{\circ} \mathrm{C}$. Macrophage-enriched fraction was harvested from the gradient by syringe, and the cells were washed three times with PBS by centrifugation $\left(200 \mathrm{x} \mathrm{g}, 10 \mathrm{~min}\right.$ at $\left.4^{\circ} \mathrm{C}\right)$. The final cell pellet was resuspented in RPMI1640 medium supplemented with $10 \%$ of FCS, and the viability of the cells was confirmed by staining with $0.5 \%$ trypan blue. The cell number was counted by a haemocytometer, and cell suspensions were diluted with the medium to appropriate concentration. The cells were cultured in $\mathrm{CO}_{2}$ incubator in a $5 \% \mathrm{CO}_{2}$ atmosphere at $25^{\circ} \mathrm{C}$.

\subsection{Bacterial infection by intraperitoneal injection}

The fish were anaesthetized with $0.02 \%$ of 2-phenoxy ethanol, and were then injected intraperitoneally with $10^{3.9} \mathrm{CFU}$ of each strain of E. tarda per $100 \mathrm{~g}$ fish body weight. Control groups were injected PBS alone. After recovery from anesthesia, each groups of 
fish was transferred to a $1000 \mathrm{~L}$ rearing tank in the flow-through system and maintained for 7 days. After 1, 2, 3, and 7 days, three fish from each group were sampled and the hepato-pancreas and kidney were aseptically removed from each fish. The isolated each organ was homogenized with a polytorone homogenizer. To measure the number of viable bacteria in each organ, the homogenized samples were serially diluted in PBS, plated on nutrient agar medium, and incubated at $27^{\circ} \mathrm{C}$ for $24 \mathrm{~h}$.

\subsection{Phogocytic assays}

The phagocytic bactericidal activities of peritoneal macrophages against two strains of E. tarda were evaluated by following procedure. To macrophage cell suspension (final 1 x $10^{6}$ cells/ml) in RPMI1640 medium supplemented with $10 \%$ FCS, each of E. tarda strain (final $5 \times 10^{5} \mathrm{CFU} / \mathrm{ml}$ ) was added. After $1 \mathrm{~h}$ incubation at $25^{\circ} \mathrm{C}$, gentamicin (final $50 \mu \mathrm{g} / \mathrm{ml}$ ) was added to the cell mixture and incubated further $1 \mathrm{~h}$ at $25^{\circ} \mathrm{C}$ to kill any remaining extracellular bacteria. The cells were washed three times with PBS to remove gentamicin, and then $1 \mathrm{ml}$ sterile distilled water was added to lyse the cells, and the number of viable intracellular bacteria was quantified by colony formation assay. To visualize the internalized bacteria, the macrophage cell suspension incubated with each strain of E. tarda, and subsequent treatment with gentamicin as described above was washed three times with PBS, and stained using Giemsa staining solution. The average number of the bacteria per macrophage was determined by counting the number of bacteria associated with macrophages, using light microscopy at a magnification of 
1000x.

\subsection{Chemiluminescence assay}

The generation of reactive oxygen species (ROS) by peritoneal macrophages was measured by the chemiluminescence (CL) assay. The assays were performed in a TR717 microplate luminometer (Applied Biosystems Foster City, CA), using 96-well white plates at $25^{\circ} \mathrm{C}$. L012 was used as a highly sensitive ROS specific chemiluminescence probe. L012 was dissolved in ultrapure water to give a concentration of $10 \mathrm{mM}$, and was stored in a small aliquots at $-30^{\circ} \mathrm{C}$. Prior to use, the L012 stock solution was thawed and diluted in PBS to a final concentration of $100 \mu \mathrm{M}$. The assay mixtures in CL assays consisted of, in order of addition, $80 \mu \mathrm{l}$ of macrophage suspension (final $10^{6} \mathrm{cells} / \mathrm{ml}$ ), $10 \mu \mathrm{l}$ of opsonized each strain of bacterial suspension (final $10^{6}$ cells/ml) or control PBS, and finally $10 \mu \mathrm{l}$ of L012 (final $10 \mu \mathrm{M}$ ). The plates were placed in the luminometer, and CL value of each well was recorded for $60 \mathrm{~min}$ at $30 \mathrm{sec}$ intervals. To examine the effect of phorbol myristate acetate on the CL responses of the macrophages exposed to each bacteria, $10 \mu \mathrm{l}$ of phorbol myristate acetate $(1 \mu \mathrm{g} / \mathrm{ml})$ solution in PBS was added to each well after 40 min recording of CL responses by the same way as described above, and then continued to record the CL responses for additional $80 \mathrm{~min}$.

2.9. Effect of E. tarda strains on CL response induced by xanthine/xanthine oxidase system 
To compare the scavenging abilities of E. tarda strains to ROS, xanthine/xanthine oxidase system was applied as a source of ROS. Ninety $\mu$ l of reaction mixture containing each strain of bacteria (final $10^{4} \mathrm{CFU} / \mathrm{ml}$ ), xanthine (final $5 \mathrm{mM}$ ) ), and L012 (final $10 \mu \mathrm{M}$ ) was put into each well of a 96-well white plate. To initiate the enzymatic reaction, $10 \mu \mathrm{l}$ xanthine oxidase (final $0.02 \mathrm{U} / \mathrm{ml}$ ) was added to each well, and then the CL intensity of each well was recorded for $30 \mathrm{~min}$.

2.10. Susceptibility of E. tarda strains to $\mathrm{H}_{2} \mathrm{O}_{2}$

The susceptibility of the low and highly virulent stains of $E$. tarda to $\mathrm{H}_{2} \mathrm{O}_{2}$ was examined. Ten $\mu$ l of each of the bacterila suspensions containing $10^{8} \mathrm{CFU} / \mathrm{ml}$ were mixed with $1 \mathrm{ml}$ of $0.01 \% \mathrm{H}_{2} \mathrm{O}_{2}$ in PBS. After incubation at $25^{\circ} \mathrm{C}$ for varying time of periods, $10 \mu \mathrm{l}$ of the aliquot of the reaction mixture was withdrawn from each reaction mixture, and the number of CFU at each incubation interval was counted by plating on nutrient agar medium in triplicate.

\subsection{Statistics}

The statistical significance of the data was determined by two-tailed Student's $t$ test, and $p<0.05$ was considered statistically significant throughout the study. 


\section{Results}

\subsection{Experimental E. tarda infection in Japanese flounder}

To confirm the differences in the virulent potential between two strains of $E$. tarda (NUF194 and NUF251), live cells of each strain were intraperitoneally inoculated into Japanese flounder, and viable bacterial cell counts in hepato-pancreas and kidney of each infected fish were investigated up to 7 days post-infection. As shown in Fig. 1, gradual increase in viable cell counts in strain NUF251 in both organs were observed. At 24 h post-infection, significant level of viable bacteria of strain NUF251 was already detected in the kidney, while appearance of viable bacteria in the hepato-pancreas was delayed and undetectable until $48 \mathrm{~h}$ post-infection. On the other hand, no viable bacteria were detected in both organs from the fish infected with strain NUF194 during 7 days experimental interval. These results clearly indicate that stain NUF251 has greater invasive potency against Japanese flounder than strain NUF194, and confirm that strain NUF251 of E. tarda is highly virulent strain, while strain NUF194 is almost avirulent.

\subsection{Phagocytosis of E. tarda by Japanese flounder macrophages}

The phagocytotic activities of Japanese flounder macrophages toward the highly virulent and low virulent strains of $E$. tarda were estimated by direct microscopic observation. As shown in Fig. 2A, these two strains were ingested into the macrophages. 
The mean number of bacteria of the virulent strain (NUF251) per macrophage evaluated by microscopic observation of Giemsa-stained macrophages was slightly higher than that of the low virulent strain (NUF194), but the difference was not statistically significant (Fig. 2B).

\subsection{Intracellular replication of E. tarda in Japanese flounder macrophages}

We compared the level of intracellular replication of two strains of E. tarda in Japanese flounder macrophages. As shown in Fig. 3, the number of viable cells gradually increased during $9 \mathrm{~h}$ incubation for the virulent strain (NUF251), whereas no significant increase in the number of viable cells of the low virulent stain (NUF194) was detected. These results suggest that the virulent strain is capable to survive and multiply within Japanese flounder macrophages, but the low virulent one had no such ability.

\subsection{ROS generation by macrophages induced by E. tarda}

To study ROS production by macrophages following incubation with E. tarda, the Japanese flounder peritoneal macrophages were incubated with each strain of $E$. tarda, and the production of ROS was investigated by chemiluminescence assay. As shown in Fig. 4, strain NUF194, a low virulent E. tarda induced significant CL response with a peak time of 7 min after the addition of bacterial cells to the macrophages. In 
contrast to strain NUF194, highly virulent strain NUF251 induced only slight CL response with nearly background level. These results suggest that the virulent strain of $E$. tarda may have the ability to prevent the activation process of ROS generation system or direct inhibition of such system. To clarify this point, the macrophage cell suspension exposed to each strain of $E$. tarda was further stimulated with phorbol myristate acetate, a potent chemical stimulant to induce ROS generation of phagocytic cells. As shown in Fig. 5, the macrophages exposed to the virulent strain induced extremely higher CL response to the stimulation by phorbol myristate acetate than that of the macrophages exposed to the low virulent strain. Probably, most part of ROS generation system in the macrophages exposed to the virulent strain remains inactive form that may be still capable to respond to the second stimulation with phorbol myristate acetate, while the macrophages exposed to the low virulent strain were already fully activated after exposure to the bacteria, and showed only slight CL response to the second stimulation.

3.5. Effects of E. tarda strains on the CL response induced by xanthine/xanthine oxidase system

One possible strategy of pathogenic bacteria to survive within phagocytes is acquisition of antioxidant or radical scavenging system such as catalase or superoxide dismutase. To ascertain whether or not this is the case for the virulent E. tarda strain, we examined the scavenging activities of E. tarda strains to $\mathrm{O}_{2}{ }^{-}$generated by xanthine/xanthine oxidase system. As shown in Fig. 6, the virulent strain reduced the 
CL response, whereas the low virulent strain had almost no effect.

3.6. Comparison of susceptibility of E. tarda strains to $\mathrm{H}_{2} \mathrm{O}_{2}$

Time course of the viabilities of $E$. tarda strains after exposure to $\mathrm{H}_{2} \mathrm{O}_{2}$ were shown in Fig. 7. The low virulent strain was killed more strongly over the $3 \mathrm{~h}$ incubation period than the highly virulent strain. These results suggest that the highly virulent strain may have extremely higher ROS-neutralizing system as compared to the low virulent strain.

\section{Discussion}

E. tarda is one of the major bacterial pathogens in freshwater and marine fish, and natural E. tarda infection has been recorded predominantly in Japanese eel, Japanese flounder, and channel catfish [16, 17], but also in many other fish species [18]. Although pathogenesis of E. tarda is considered to be multifactorial, and several potential virulence factors have been reported so far [6-9], the details of the pathogenic mechanism is still controversial. Comparative studies of virulent and avirulent strains have demonstrated that only the virulent strain could enter fish and multiply inside various internal organs, and caused eventual fish death, even though both virulent and avirulent strains had the similar ability to invade cultured cells in vitro [19]. In the investigation of the pathogenic characteristics of 35 Edwardsiella strains, it was found 
that pathogenic potency of E. tarda did not correlate with plasmid content, chemotactic mobility, serum resistance, or expression of selected enzyme activities [20]. Based on these findings, it seems likely that some virulent $E$. tarda strains acquire the specific strategy to overcome fish defense system against pathogens. In general, humoral and cellular innate immune systems are the two major defense mechanisms against invading bacterial in fish. Thus the acquisition of resistance to these defense mechanisms by pathogens leads to severe infection. For instance, it has been shown that virulent fish pathogens such as Aeromonas hydrophila [21, 22] and Renibacterium salmoninarum [23] are resistant to serum- and phagocyte-mediated killing. In the present study, the experimental infection of Japanese flounder with a low and a highly virulent E. tarda strains was conducted. In naturally infected fish and experimentally infected Japanese flounder and channel catfish, it has been reported that significant pathological changes in the kidney and liver were observed, most often in the form of abscesses and necrotic lesions [24]. Therefore, we examined viable bacterial cell counts in kidney and hepato-pancreas that are supposed to be the major target organs of E. tarda in the infected fish. The infection kinetics showed that only the highly virulent strain showed a sequential increase in the number of viable bacterial cells within both organs, whereas the levels of low virulent strain within these organs were less than the detectable limit throughout the postinfection period. Thus it is obvious that strain NUF251 is highly virulent E. tarda as compared to strain NUF194 that may be even avirulent, and strain NUF251 is capable to multiply within the internal organs by overcoming Japanese flounder defense system. To further evaluate the escape mechanism of strain NUF251 
from fish defense system, in vitro analysis with isolated fish macrophages was done in which we investigated the ability of these bacterial strains to survive and multiply within macrophages. The assay to determine the number of intracellular viable cells of the virulent and the low virulent $E$. tarda strains revealed that only the virulent strain NUF251 could replicate within macrophages. Similar to E. tarda, it has been reported that the ability to survive inside host macrophages is an essential virulence requirement for Salmonella [12], and Salmonella phoP mutants are avirulent due to their inability to survive in macrophages [13].

In phagocytes such as macrophages and neutrophils, the generation of ROS through respiratory burst is one of the major bactericidal mechanisms. This oxygen-dependent bactericidal mechanism has been demonstrated in phagocytes of many different fish species [22, 23, 25, 26]. In mammalian phagocytes, it has been well documented that the generation of ROS occurs via a membrane-bound flavocytochtome b558, consisting two phagocytic oxidase (phox) components (gp91phox and p22phox) and four cytosolic components (p40phox, p47phox, p67phox, and a GTP-binding Rac protein). During stimulation, the cytosolic components translocate to the site of gp91phox/p22phox on the phagosomal membrane to form a functional enzyme complex which generates superoxide anion $\left(\mathrm{O}_{2}{ }^{-}\right)$by catalyzing electron transfer from NADPH to molecular oxygen [27]. Several lines of evidence suggest that similar enzymatic system is responsible for the ROS generation in fish phagocytes [28].

In the present study, we found that the virulent E. tarda strain induced only a trace level of ROS production by Japanese flounder peritoneal macrophages in vitro as 
measured by chemiluminescence (CL) response analysis, whereas low virulent strain induced ROS production with significantly higher level. Similar to our virulent $E$. tarda strain, several bacteria are known to have the ability to escape the phagocyte respiratory burst, resulting in successful intracellular survival [25, 29]. In contrast, it has been reported that higher production of ROS in rainbow trout macrophages was induced by the highly virulent strain of Flavobacterium psychrophilum than by the low virulent strain, even though the virulent strain was more resistant to macrophage-mediated killing activity than low virulent strain. Therefore, it appears that the strategy to survive inside macrophage is depending on bacterial species, and they might evolve indigenous specific ability to overcome the phagocyte-mediated defense system. In principle, there are two effective mechanisms for resisting or avoiding ROS-mediated phagocytic microbicidal activity: Namely, (i) blocking of the elicitation of respiratory burst or inhibition of the activity itself, or (ii) neutralization of the ROS produced during the respiratory burst. In fact, regarding the possibility (i), Edwardsiella ictaluri LPS has been reported to suppress CL response of catfish neutrophils to opsonized zymosan [30]. When the macrophages exposed to the virulent strain of E. tarda were further stimulated with phorbol myristate acetate, extremely high CL response was induced. Therefore, it is considered that the ROS generation system in the macrophages exposed to the virulent strain remained inactive form that is still capable to respond to other stimulation to convert to active form. In other word, the virulent strain of $E$. tarda may prevent the activation process of ROS generation system in the macrophages rather than the irreversible inhibition of the activity itself. 
On the other hand, some bacteria are known to resist ROS by producing SOD or catalase [31-33] that may be related to the notion (ii) described above. To ascertain whether or not the virulent E. tarda strain (NUF251) has such neutralizing activities against ROS with greater level than the low virulent strain (NUF194), we investigated the effects of the E. tarda strains on the CL response caused by xanthine/xanthine oxidase system in which $\mathrm{O}_{2}{ }^{-}$is continuously produced as a byproduct of the enzyme reaction. Although the virulent strain apparently reduced the CL response, the low virulent strain had almost no effect. To further clarify the possible presence of neutralizing activity against ROS in the virulent strain, the cytotoxic effects of $\mathrm{H}_{2} \mathrm{O}_{2}$ on the strains were examined. The results clearly indicated that there is significant difference in the susceptibility to $\mathrm{H}_{2} \mathrm{O}_{2}$ between two strains, and the virulent strain showed more stronger resistance to $\mathrm{H}_{2} \mathrm{O}_{2}$-mediated killing than the low virulent strain. These results suggest that the inability of the virulent strain to induce potent CL response by fish macrophages is due to the scavenging or neutralizing ROS produced during phagocytosis in addition to the prevention of activation process of ROS generation system. Such abilities of the virulent strain may allow the organism to survive and multiply within macrophages. Similar to the virulent strain of E. tarda observed in this study, Aeromonas salmonicida and Photobacterium damselae subsp. piscicida are shown to resist oxidative killing by producing SOD [31, 32]. More recent study has also demonstrated that the expression of catalase in E. tarda is required for resistance to $\mathrm{H}_{2} \mathrm{O}_{2}$ and phagocyte-mediated killing [9]. The presence or enhanced expression of one of such defense mechanisms in the highly virulent strain may account 
for higher resistance to killing by ROS, and may serve to disseminate E. tarda in the host during in vivo infection. Hence, resistance to bacterial killing by the macrophages may be an important virulent factor of E. tarda.

In conclusion, the present study demonstrated that the virulent E. tarda has multiple defense systems against ROS produced during phagocytosis to survive and multiply within fish macrophages. Such ability may serve as a major virulence factor of E. tarda.

\section{Acknowledgements}

This work was supported in part by a Grant-in-Aid for Scientific Research from Nagasaki University, Japan, and by grants from Nagasaki Prefecture collaboration of Regional Entities for Advancement of Technological Excellence, Japan Science and Technology Agency, and from the Ministry of Education, Science, Sports and Culture, Japan.

\section{References}

[1] Plumb JA. Edwardsiella Septicaemias. In: Woo PTK, Bruno DW, editors. Fish diseases and disorders, volume 3; viral, bacterial, and fungal infections, vol. 3. Oxon, UK: CAB International; 1999. p. 479-521.

[2] Kourany M, Vasquez MA, Saenz R. Edwardsiellosis in man and animals in Panama: 
clinical and epidemiological characteristics. Am J Trop Med Hyg 1977;26: 1183-1190.

[3] Goldstein EJC, Agyare EO, Vagvolgi AE, Halpern M. Aerobic bacterial oral flora of garter snakes: development of normal flora and pathogenic potential for snakes and humans. J Clin Microbiol 1981;13: 954-956.

[4] Cook RA, Tappe JP. Chronic enteritis associated with Edwardsiella tarda infection in Rockhopper penguins. J Am Vet Med Assoc 1985;187: 1219-1220.

[5] Janda JM, Abbott SL. Infections associated with the genus Edwardsiella: the role of Edwardsiella tarda in human disease. Clin Infect Dis 1993;17: 742-748.

[6] Ullah MA, Arai T. Pathological activities of the naturally occurring strains of Edwardsiella tarda. Fish Pathol 1983;18: 65-70.

[7] Hirono I, Tange N, Aoki T. Iron-regulated haemolysin gene from Edwardsiella tarda. Mol Microbiol 1997;24: 851-856.

[8] Ling SHM, Wang XH, Xie L, Lim TM, Leung KY. Use of green fluorescent protein (GFP) to track the invasion pathways of Edwardsiella tarda in in vivo and in vitro fish models. Microbiology 2000;146: 7-19.

[9] Srinivasa Rao PS, YamadaY, Leung KY. A major catalase (KatB) that is required for resistance to $\mathrm{H}_{2} \mathrm{O}_{2}$ and phagocyte-mediated killing in Edwardsiella tarda. Microbiology 2003;149: 2635-2644.

[10] Babior BM. Microbicidal oxidant production by phagocytes, In Oxy-radicals in Molecular Biology and Pathology, eds Cerutti PA, Fridovich I, McCord JM, Alan RL Inc., New York, 1988. p. 39-51. 
[11] Moritomo T, Iida T, Wakabayashi H. Chemiluminescence of neutrophils isolated from peripheral blood of eel. Fish Pathol 1988;23: 49-53.

[12] Fields PI, Swanson RV, Haidaris CG, Heffron F. Mutants of Salmonella typhimurium that cannot survive within macrophages are avirulent. Proc Natl Acad Sci USA 1986;83: 5189-5193.

[13] Miller SI, Mekalanos JJ. Constitutive expression of the phoP regulon attenuates Salmonella virulence and survival within macrophages. J Bacteriol 1990;172: 2485-2490.

[14] Osatomi K, Kanai K, Hara K, Ishihara T. Changes in Cu, Zn-SOD activity in Japanese flounder Paralichthys olivaceus with bacterial infection (in Japanese with English abstract). Nippon suisan Gakkaishi 2002;68: 207-213.

[15] Suprapto H, Hara T, Nakai T, Muroga K. Purification of a lethal toxin of Edwardsiella tarda. Fish Pathol 1996;31: 203-207

[16] Kusuda R, Salati F. Major bacterial diseases affecting mariculture in Japan. Ann Rev Fish Dis 1993;3: 69-85.

[17] Darwish A, Plumb JA, Newton JC. Histopathology and pathogenesis of experimental infection with Edwardsiella tarda in Channel Catfish. J Aquat Anim Health 2000;12: 255-266.

[18] Thune RL, Stanley LA, Cooper RK. Pathogenesis of gram-negative bacterial infections in warm water fish. Annu Rev Fish Dis 1993;3: 37-68.

[19] Ling SHM, Wang XH, Lim TM, Leung KY. Green fluorescent protein-tagged Edwardsiella tarda reveals portal of entry in fish. FEMS Microbiol Lett 2001;194: 
239-243.

[20] Janda JM, Abbott SL, Kroske-Bystrom S, Cheung WKW, Powers C, Kokka RP, Tamura K. Pathogenic properties of Edwardsiella species. J Clin Microbiol 1991;29: 1997-2001.

[21] Leung KY, Yeap IV, Lam TJ, Sin YM. Serum resistance is a good indicator of virulence in Aeromonas hydrophila strains isolated from diseased fish in South-East Asia. J Fish Dis 1995;18: 511-518.

[22] Leung KY, Low KW, Lam TJ, Sin YM. Interaction of fish pathogen Aeromonas hydrophila with tilapia, Oreochromis aureus (Stein-dachner), phagocytes. J Fish Dis 1995;18: 435-447.

[23] Bandin I, Rivas C, Santos Y, Secombs CJ, Barja JC, Ellis AE. Effect of serum factors on the survival of Renibacterium salmoninarum within rainbow trout macrophages. Dis Aquat Org 1995;23: 221-227.

[24] Rashid MM, Nakai T, Muroga K, Miyazaki T. Pathogenesis of experimental Edwardsiellosis in Japanese Flounder Paralichthys olivaceus. Fish Sci 1997;63: 384-387.

[25] Bandin I, Ellis AE, Barja JL, Secombs CJ. Interaction between rainbow trout macrophages and Renibacterium salmoninarum in vitro. Fish Shellfish Immunol 1993;3: 25-33.

[26] Yin Z, Lam TJ, Sin YM. Cytokine-mediated antimicrobial immune response of catfish, Clarias gariepinus, as a defense against Aeromonas hydrophila. Fish Shellfish Immunol 1997; 7: 93-104. 
[27] Segal AW, Shatwell KP. The NADPH oxidase of phagocytic leucocytes. Ann NY Acad Sci 1997;832: 215-222.

[28] Shiibashi T, Iida T. NADPH and NADH serve as electron donor for the superoxide-generating enzyme in tilapia (Oreochromis niloticus) neutrophils. Dev Comp Immunol 2001;25: 461-465.

[29] Shimoji Y, Yokomizo Y, Mori Y. Intracellular survival and replication of Erysipelothrix rhusiopathiae within murine macrophages: failure of induction of the oxidative burst of macrophages. Infect Immun 1996;64: 1789-1793.

[30] Waterstrat PR, Ainsworth AJ, Capley G. In vitro responses of channel catfish, Ictalurus punctatus, neutrophils to Edwardsiella ictaluri. Dev Comp Immunol 1991;15: 53-63.

[31] Barnes AC, Balebona MC, Horne MT, Ellis AE. Superoxide dismutase and catalase in Photobacterium damselae subsp, piscicida and their roles in resistance to reactive oxygen species. Microbiology 1999;145: 483-494.

[32] Barnes AC, Horne MT, Ellis AE. Effect of iron on expression of superoxide dismutase by Aeromonas salmonicida and associated resistance to superoxide anion. FEMS Microbiol Lett 1996;142: 19-26.

[33] Sanchez-Moreno M, Monteoliva-Sanchez M, Ortega F, Ramos-Cormenzana A, Monteoliva M. Superoxide dismutase in strains of the genus Flavobacterium: isolation and characterization. Arch Microbiol 1989;152: 407-410. 


\section{Figure legends}

Fig. 1. Time course analysis of viable cell counts of intraperitoneally injected highly virulent (NUF251) ( $\mathbf{a}$ ) and low virulent (NUF194) ( $\square$ ) E tarda strains in the hepato-pancreas (A) and the kidney (B) of Japanese flounder. At the indicated period of the time, three fish each were sampled, and hepato-pancreas (A) and kidney (B) were dissected and homogenized, and number of viable bacteria was determined by colony formation assay. Each point represents an average of triplicate measurements. Each bar represents standard deviation. a: not detectable (less than detectable limit).

Fig. 2. Phagocytic ingestion of E. tarda strains by Japanese flounder macrophages. (A) After $1 \mathrm{~h}$ incubation of Japanese flounder peritoneal macrophages with opsonized highly virulent (a) or low virulent strain (b) of E. tarda, cells were treated with gentamicin (final $50 \mu \mathrm{g} / \mathrm{ml}$ ) for $1 \mathrm{~h}$ at $25^{\circ} \mathrm{C}$ followed by fixing with $100 \%$ methanol and staining with Giemsa staining solution, and then observed microscopically. Each bar indicates $10 \mu \mathrm{m}$. (B) To determine the mean number of ingested bacteria per macrophage, numbers of bacteria of more than 10 macrophages were counted. The difference in the mean number of bacteria per macrophage between two strains was not statistically significant $(P>0.05)$.

Fig. 3. Intracellular multiplication of the highly virulent (NUF251) (O) and the low virulent (NUF194) (O) of E. tarda strains in Japanese flounder peritoneal macrophages. Macrophages were incubated with each strain of bacteria with bacteria/macrophage of 
1:2. After the incubation for the indicated period of the time, cells were treated with gentamicin (final $50 \mu \mathrm{g} / \mathrm{ml}$ ) for $1 \mathrm{~h}$, and then lysed with sterile distilled water. The number of viable bacteria in each cell lysate was determined by colony formation assay. Each point represents an average of triplicate measurements. Each bar represents standard deviation. Asterisks indicate significant differences between two stains (* $P<0.05)$.

Fig. 4. Chemiluminescent responses of Japanese flounder peritoneal macrophages to opsonized highly virulent (NUF251) (O) and low virulent (NUF194) (O) E tarda strains. Macrophages (final $10^{6}$ cells/ml) were exposed to opsonized each strain of bacteria (final $10^{6} \mathrm{CFU} / \mathrm{ml}$ ). After addition of L012 (final $10 \mu \mathrm{M}$ ) with equipped injector, the chemiluminescent responses were recorded immediately. $(X)$ : control CL response of macrophages without bacteria.

Fig. 5. Effects of phorbol myristate acetate on the chemiluminescent responses of Japanese flounder peritoneal macrophages exposed to opsonized highly virulent (NUF251) (O) and low virulent (NUF194) (○) E tarda strains. Macrophages (final $10^{6}$ cells/ml) were exposed to opsonized each strain of bacteria (final $10^{6} \mathrm{CFU} / \mathrm{ml}$ ). After addition of L012 (final $10 \mu \mathrm{M}$ ) with equipped injector, the chemiluminescent responses were recorded immediately. After 40 min recording , phorbol myristate acetate (final 0.1 $\mu \mathrm{g} / \mathrm{ml}$ ) was added to each reaction mixture at the time indicated with arrow, and continued to record the CL responses. $(X)$ : control CL response of macrophages alone 
without bacteria and phorbol myristate acetate.

Fig. 6. Effects of viable bacteria of highly virulent (NUF251) and low virulent (NUF194) $E$ tarda strains on the chemiluminescent responses induced by xanthine/xanthine oxidase system. In the presence of E. tarda strain NUF251 (O) or NUF194 (O) (final $10^{4} \mathrm{CFU} / \mathrm{ml}$ ), the chemiluminescent responses induced by $5 \mathrm{mM}$ of xanthine and $0.02 \mathrm{U} / \mathrm{ml}$ of xanthine oxidase were measured. $(X)$ : control chemiluminescent response without bacteria.

Fig. 7. Viability of highly virulent (NUF251) (O) and low virulent (NUF194) (O) E tarda strains after exposure to $\mathrm{H}_{2} \mathrm{O}_{2}$. Each bacterial strain $\left(10^{8} \mathrm{CFU} / \mathrm{ml}\right)$ was exposed to final $0.01 \% \mathrm{H}_{2} \mathrm{O}_{2}$. After the indicated period of the time, the numbers of the viable cells were determined by colony formation assay. Each point represents an average of triplicate measurements. Each bar represents standard deviation. Asterisks indicate significant differences between two stains $\left({ }^{*} P<0.05\right)$. 
Fig .1

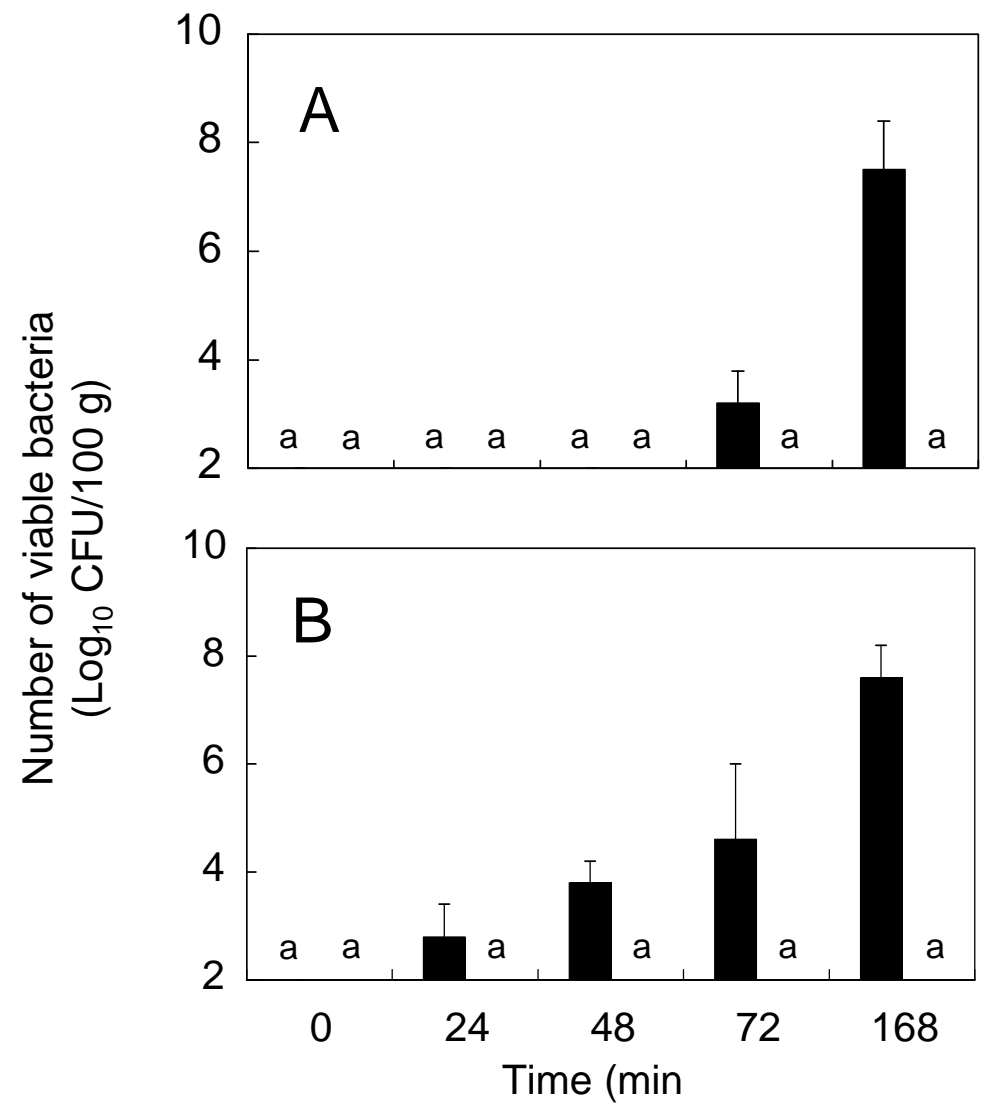


Fig.2
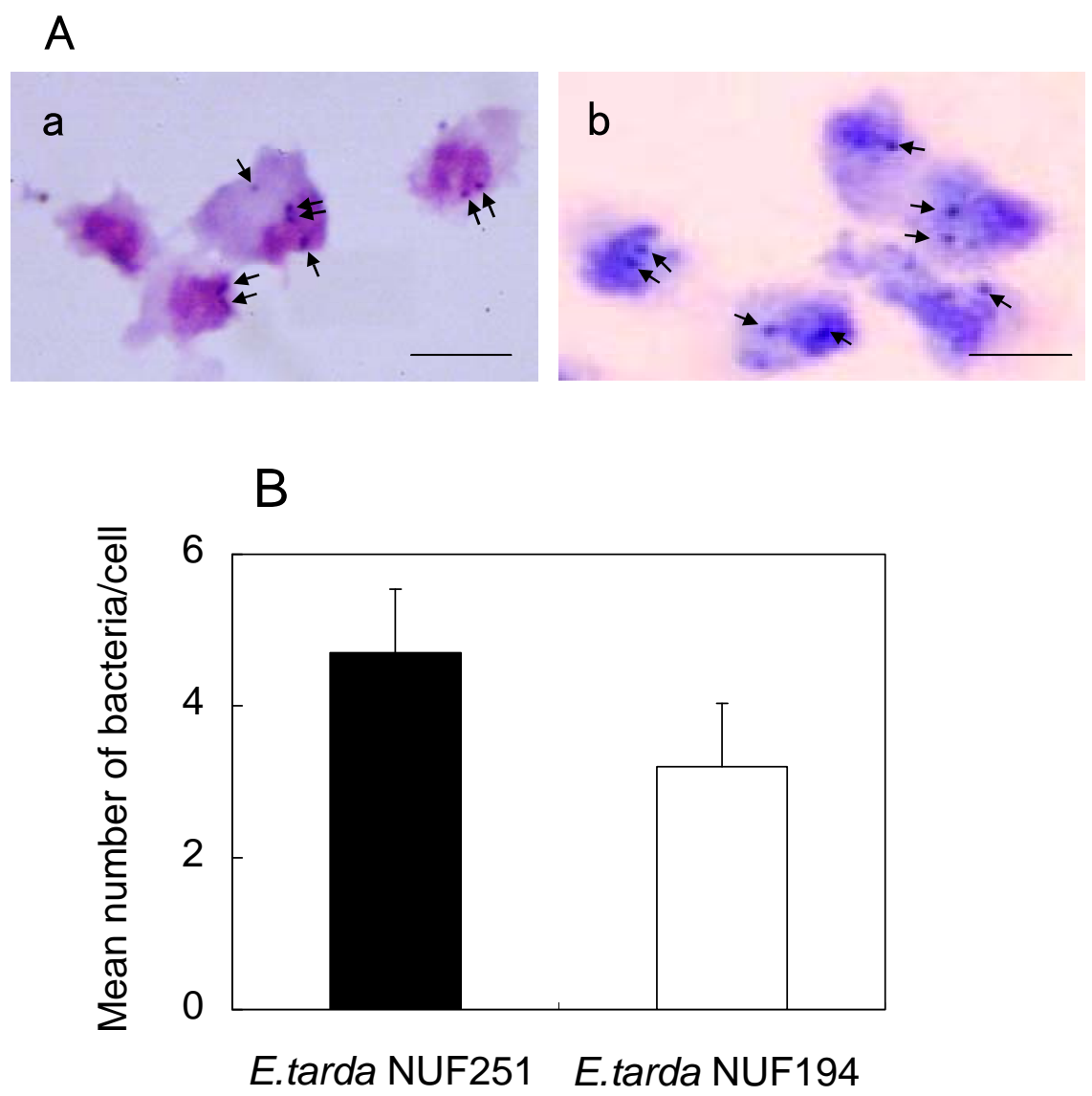
Fig.3

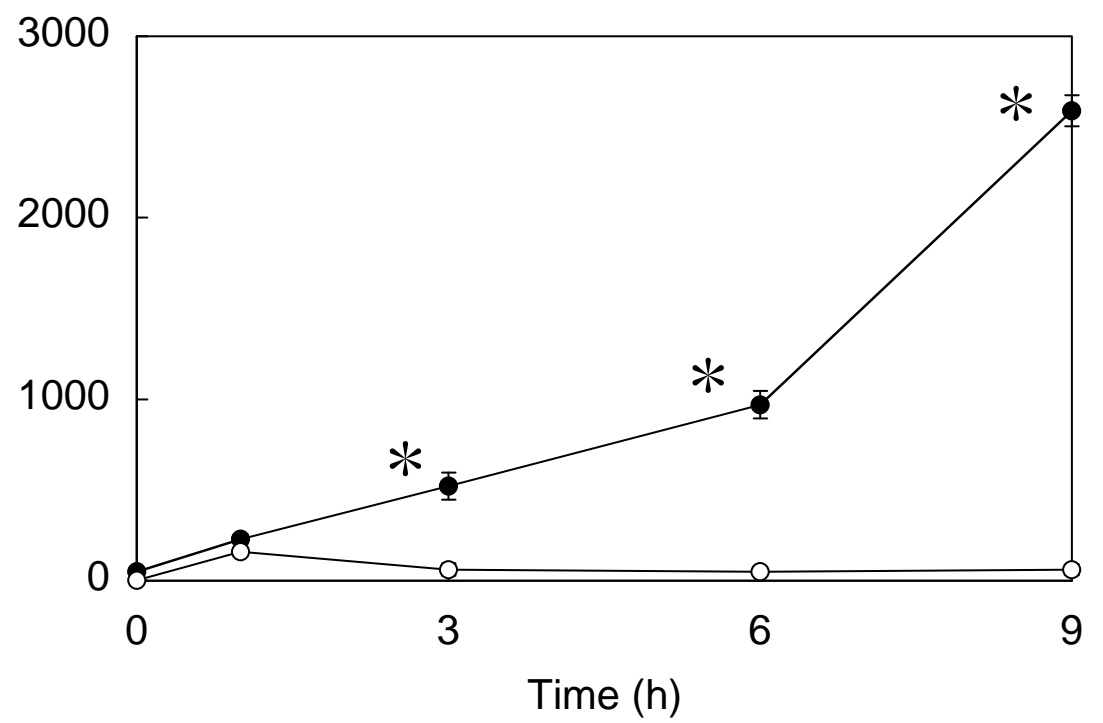


Fig.4

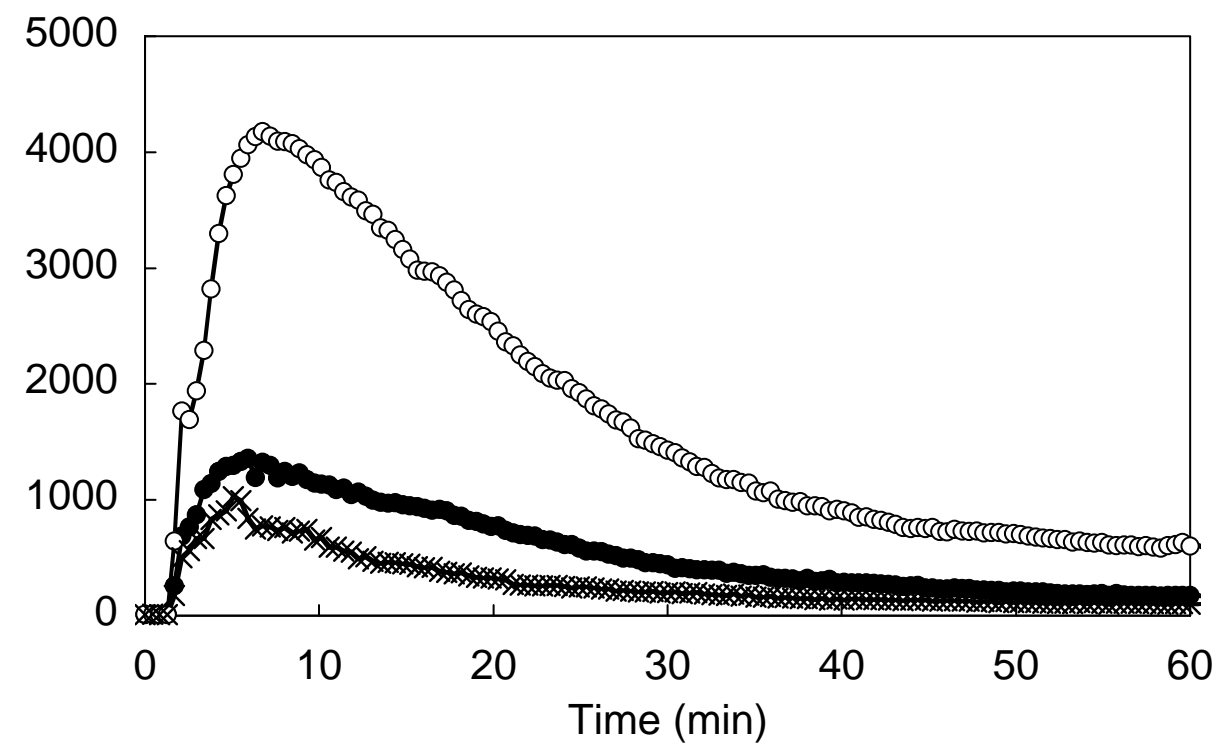


Fig.5

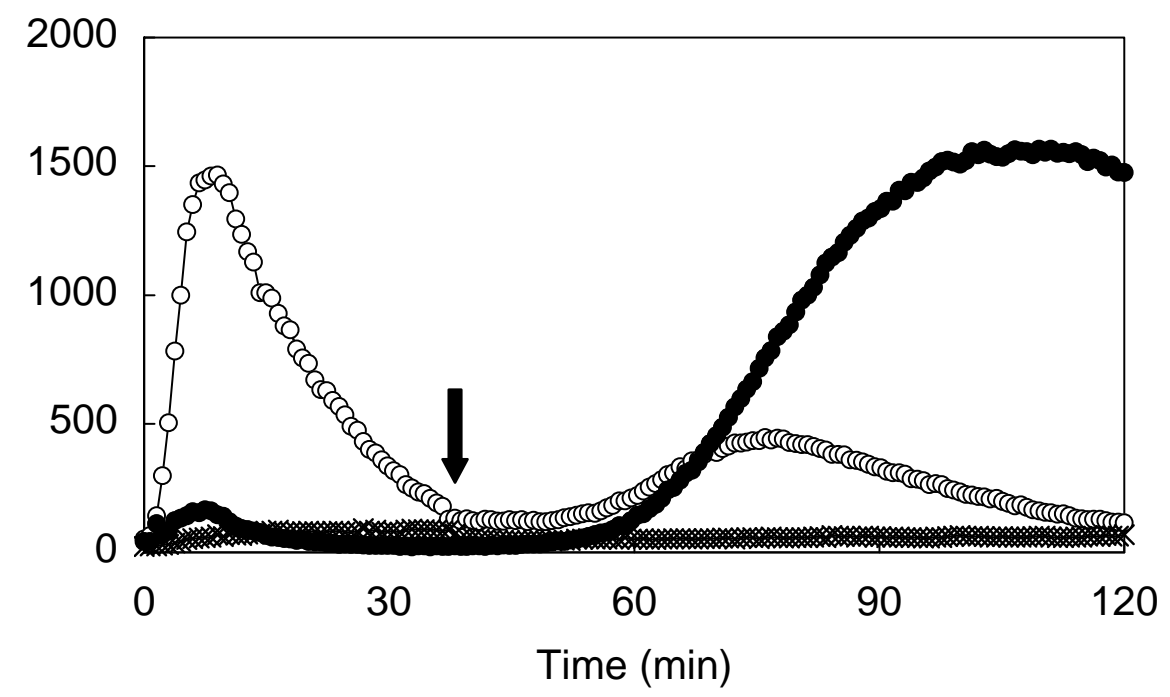


Fig.6

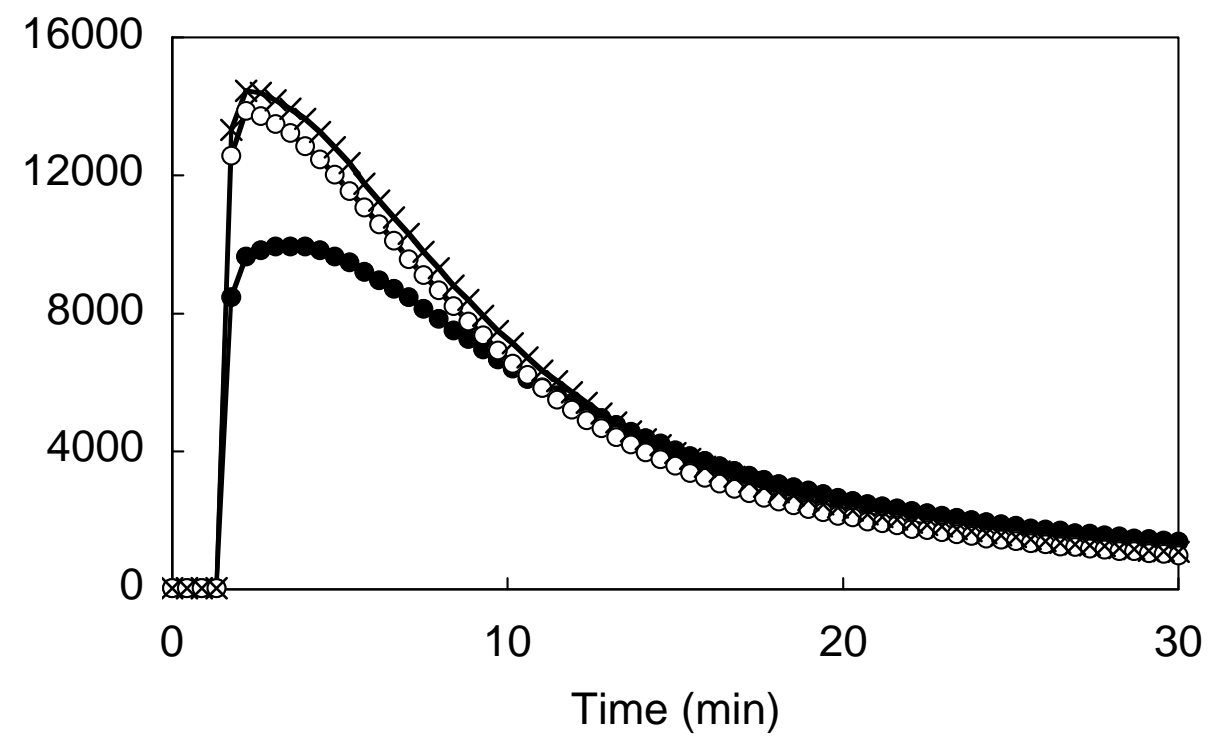


Fig. 7

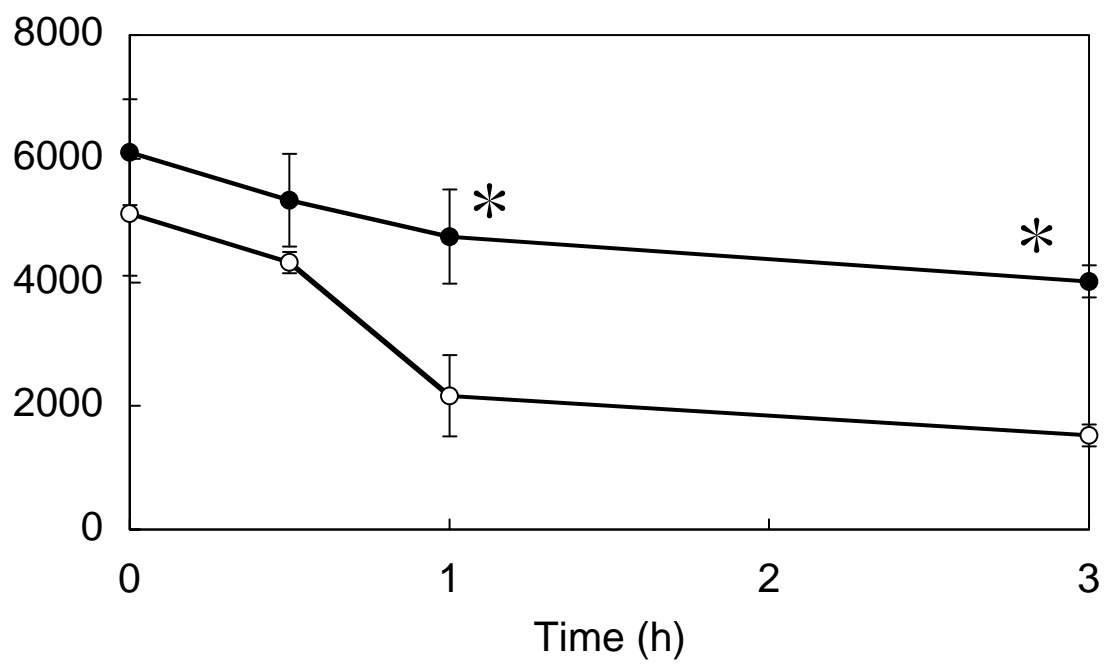

